\title{
Beşiktaş Jimnastik Kulübü Basketbol Altyapı Takımları Antrenörlerinin Liderlik Özelliklerinin Belirlenmesi $^{1}$
}

DOI: 10.26466/opus.577979

\author{
Ayșe Demir* - Betül Bayazıt** - Serap Çolak*** \\ *Doktora Öğrencisi, Kocaeli Üniversitesi Sağlık Bilimleri Enst., Kocaeli/Türkiye \\ E-Posta: aysem.demir34@gmail.com \\ ORCID: $\underline{0000-0002-3856-0498}$ \\ **Doç. Dr., Kocaeli Üniversitesi Spor Bilimleri Fakültesi Kocaeli/Türkiye \\ E-Posta: betul.bayazit@kocaeli.edu.tr \\ ORCID: $0000-0003-3547-2035$ \\ ***Doç. Dr., Kocaeli Üniversitesi Spor Bilimleri Fakültesi Kocaeli/Türkiye \\ E-Posta: serap.colak@kocaeli.edu.tr \\ ORCID: $\underline{0000-0003-3093-0607}$
}

Öz

Liderlik temel anlamda, insanları belirlenmiş bir amaca yönelik gönüllü olarak yöneltmeyi ikna etme yeteneği olarak tanımlanmaktadır. Bu çalışmanın amacı, Beşiktaş Jimnastik Kulübü Basketbol altyapı takım sporcularının antrenörleri hakkındaki liderlik özelliklerinin belirlenmesidir. Araştırmaya, Beşiktaş Jimnastik Kulübü Basketbol Altyapı takımlarında (U18,U16,U15,U24,U13,U12,U11) spor faaliyetini aktif olarak sürdüren 101'i kadın $(\% 55,2)$ ve 82'si erkek $(\% 44,8)$ olmak üzere toplam 183 sporcu gönüllü olarak katılmıştır. Araştırmada "Alg̨lanan Liderlik Ölçeğì" kullanılarak veriler toplanmıştır. Ölçek, 5'li Likert tipi puanlamaya sahiptir ve 36 maddeden oluşmaktadır. Elde edilen veriler doğrultusunda, takım oyuncularının antrenörleri hakkındaki liderlik ölçeği toplam puanları (işgören, üretim, değişim) açısından takımlar arasında istatistiksel olarak anlamlı bir farklılık bulunmuştur ( $p<0.05)$. Takımların cinsiyet değişkenine göre liderlik toplam puanlarında da (işgören, üretim, değişim) istatistiksel olarak anlamlı bir farklılık bulunmuştur $(p<0.05)$. Araştırmaya katılan kadın sporcuların antrenörleri hakkında algıladıkları işgören, üretim ve değişim liderlik davranış özelliklerini erkek sporculara göre daha fazla benimsedikleri sonucuna varılmıştır. Bu da kadınların antrenörleri hakkındaki liderlik algıları açısından erkeklere nazaran daha hassas oldukları sonucunu doğurmuştur.

Anahtar Kelimeler: Liderlik, Antrenör, Sporcu

\footnotetext{
${ }^{1}$ Bu çalışma 10-13 Mayıs 2018 tarihleri arasında Bodrum-Türkiye'de düzenlenen Uluslararası Rekreasyon ve Spor Yönetimi Kongresi'nde sözel bildiri olarak sunulmuştur.
} 


\title{
Designating The Leadership Specialities of The Coaches of Besiktas Gymnastic Club's Youth Teams
}

\begin{abstract}
Leadership is, basically, defined as the ability to convince people to orientate as volunteer for a defined aim. The aim of this study is to determine the leadership qualities of Beşiktaş Gymnastic Club basketball infrastructure team athletes' coaches. 101 (female) (55.2\%) and 82 (male) (44.8\%), which are active in sports activities in Beşiktaş Gymnastic Club Basketball Infrastructure teams (U18, U16, U15, U24, U13, U12, U11), a total of 183 athletes were voluntarily participated to the research. Data were collected using the "Perceived Leadership Scale" in the study. According to the data obtained, statistically significant differences were found between the teams in terms of total scores (occupation, production, change) of leadership scale for team players' coaches $(p<0.05)$. A statistically significant difference ( $p$ $<0.05)$ with total leadership scores (occupation, production, change) according to the gender variable of the teams was also found. It was concluded that female athletes participating in the research adopted the occupational, production and change leadership behavior properties about their coaches more than male athletes. This infers that women are more sensitive than men in terms of leadership perceptions about their coaches.
\end{abstract}

Keywords: Leadership, Coach, Athlete 


\section{Giriş}

Takım sporlarında, antrenörler takımın tüm yönlerinden ve ayrıca sporcuların performansından sorumludur; bu nedenle kararları ve eylemleri kilit bir rol oynar ve hem bireysel seviyesini hem de ekiplerinin iç dinamiklerini etkiler (Brandão ve Carchan, 2010; Kleinert ve ark., 2012). Bu anlamda, bir spor takımı sporcular arasındaki bireysel farklılıklar (örneğin, fiziksel ve zihinsel beceriler, spor becerileri, psikolojik eğilimler, vb.) ve antrenörlerin davranışları gibi çeşitli etkilere maruz kalır (Fenoy ve Campoy, 2012; Ponseti ve diğerleri, 2012; Vella ce ark., 2013).

Spor alanındaki araştırmada, takımların işleyişini tanımlayan temel kavramlardan ikisi uyum ve işbirliğidir. Olmedilla ve arkadaşları (2011, s. 232), "uyum, sosyal bağlllık seviyesiyken (ister grup isterse görev olsun) işbirliği, kişisel ve takım hedeflerinin peşinden koşmak ve ekip davranışlarını oluşturmak için bunların birleşimidir". Bu anlamda, spor işbirliği paradigması, takım içindeki etkileşimleri ve işbirliği ile rekabet arasındaki bireysel ikilemi açıklama ihtiyacından doğar ve spor takımlarının dinamiğinin anlaşılmasına katkıda bulunan bir çerçeve olarak görülebilir (Almeida ve Lameiras, 2013).

Günümüzde spor işbirliği, bireysel ve kolektif hedeflerin peşinde koşma ve belirli bir spor davranışını üretme kombinasyonları olarak tanımlanmaktadır (GarcíaMas ve ark., 2009; Olmedilla ve ark., 2011). Ayrıca, belirli hedeflere ulaşmayı hedefleyen bireyler arasındaki etkileşimi ve spor takımına entegrasyonunu temel alan dinamik karar verme olarak da tanımlanabilir (Olmedilla ve ark., 2011).

Ek olarak, sportif işbirliği, oyuncunun çabalarının ve teknik becerilerinin ekibin hedefine ithaf edilmesine ilişkin kişisel kararlarını yansıtan bir sosyal davranış biçimi olarak da anlaşılabilir (Almeida ve Lameiras, 2013; García-Mas ve ark., 2006; Lameiras ve ark., 2014). Bu anlamda ve onların etkisinden dolayı, antrenörlerin liderlik stilleri, sporcuların sorumluluklarını ve kişisel çabalarını yerine getirdiği ortamı şekillendirir ve sporcuların kooperatif (dolayısıyla sosyal) davranışlarını etkileyebilir (Sarı ve ark., 2013; Spink ve ark., 2013).

García-Mas ve arkadaşları (2006), oyuncuların davranışlarının gözlenebildiğinin, kısmen ortak bir hedefle ilgili olarak işbirliği yapıp yapmama kararına bağlı olacağı varsayımına dayanan kavramsal bir 
çerçeve önermiştir. Bu karar, işbirliği yapma veya rekabet etme eğilimini veya bağlamsal değişkenlerle ilgili belirli durumsal faktörleri yansıtan daha istikrarlı bir eğilim faktörüne dayanarak verilebilir. Yazarlar, bu iki eğilimsel işbirliği türü arasında bir ayrım önermiştir: koşullu işbirliğ $i$ (kişisel hedeflere ulaşılmasından bağımsız olarak gerçekleşir) ve koşulsuz işbirliği (sporcunun harcadığı çabanın, takımın bir parçası olarak ulaşılabilecek kişisel hedeflerin algılanmasıyla koşullandırıldığını tarif etmek).

Aynı yazarlar tarafından önerilen bir başka varsayım, temel olarak rasyonel kişisel çıkar algılarından türetilen durumsal işbirliğinin varlığı ile ilgilidir. Bu durumsal faktörler iki kategoride gruplandırılmıştır: nerede (sahanın içinde veya dişında) ve kiminle (bu takım arkadaşları ile işbirliği ve koç ile işbirliği arasında bölünmüştür) işbirliği yapmalı (Almeida ve Lameiras, 2013). Bu anlamda, sporcular fiziksel, teknik ve taktiksel çabalarını, takım arkadaşları veya antrenörlerle oluşturulmuş etkileşimin bir karşılığı olarak hedeflerine ulaşabilecekleri algısı sayesinde adamaya karar vermekte ve bu telafi edici ilişki sahada antrenman sırasında veya rekabet halindeyken ortaya çıabilmektedir (García-Mas ve ark., 2009; Olmedilla ve ark., 2011).

Özellikle antrenörle olan işbirliğine ilişkin olarak, atletler kooperatif davranışlarını, kendi hedeflerine ulaşma fırsatı elde etmek için koçtan gelen talimatlara uyarak ve onları izleyerek yardımcı olurlar (García-Mas ve ark., 2009; Lameiras ve ark., 2014; Olmedilla ve ark., 2011). Aslında, antrenörlerin liderlik stilinin önemini ve insanları, kısmen takımın uyum düzeyini ve kooperatif davranısını belirleyebilecek, ortak bir hedefe ulaşmak için birlikte çalışabileceklerini etkileme kapasitelerini vurgulama konusunda geniş bir fikir birliği vardır (Carvalho ve ark., 2013; Swanson ve Kent, 2014).

Etkili liderlik sadece tutku ve vizyon sahibi olmayı gerektirmez, aynı zamanda yeterli liderlik becerilerine ve baskı altında çalışabilme yeteneğine sahip olmayı da gerektirir. Yöneticilerden farklı olarak, etkili liderler bir spor kuruluşunun yalnızca iç sistemlerini değil, aynı zamanda dış ortamını da anlamalarını sağlamalıdırlar. Liderler, yüksek derecede esneklik ve bilgi birikimi gerektiren yeni ve zorlu durumlara sürekli maruz kalırlar. Kurumlarını ilerletmek için, bugünün liderlerinin dönüşümcü liderliği uygulamaya ihtiyacı var. İşlem modeline kıyasla dönüşümsel liderlik, acil ihtiyaçların karşılanmasından daha fazlasıdır. Bu, 
liderin izleyicilerinin potansiyel motivasyonlarını tanımlamasından ve ortak ve paylaşılan bir hedef yaratmasından ibarettir. Dönüşümcü liderlik, vizyonun öneminin yanı sıra, entellektüel uyarımın ve liderlikte bireyselleştirilmiş düşünmenin önemini de vurgulamaktadır (Sauer, 2017).

Spor organizasyonlarının karmaşıklığı ve örgütsel değişimin zorluğu, etkili liderliği sağlamak için profesyonel eğitim gerektirir. Görünen o ki, spor organizasyonlarının iş çevreleri, temel olarak 10 yıl öncesinden farklıdır. Organizasyonlar, aşırı bilgi yükü taşıyan liderlerden kaçınmaya çalışmalı, durumları ve bilgileri en verimli şekilde nasıl yorumlayacaklarını tam olarak bilenlere yönelmelidir. Son yıllarda, artan sayıda kuruluş bu liderleri desteklemek ve liderlik geliştirme programları kurmak için bu ihtiyacı kabul etmiştir (Sauer, 2017). Bu kapsamda, yürütülen bu araştırmanın amacı, sporcuların antrenörlerin liderlik davranışlarına ilişkin algılarını incelemek ve takım sporu ile uğraşan sporcuların antrenörlerinin liderlik özelliklerine yönelik algıları ile antrenörlerin temel liderlik özelliklerinin belirlenmesi hedeflenmektedir.

\section{Materyal ve Metot}

\section{Araştırma Modeli}

Bu çalışma Beşiktaş Jimnastik Kulübü Basketbol Altyapı takımları sporcularının antrenörleri hakkındaki liderlik özelliklerinin belirlenmesini amaçlayan bu araştırmada nicel araştırma yöntemlerinden betimsel tarama modeli kullanılmıştır. Betimsel tarama, bir değişkene ilişkin sayısal değerlerin toplanması, betimlenmesi ve sunulmasına olanak sağlayan istatistiksel işlemlerdir (Büyüköztürk ve ark. 2014).

\section{Çalışma Grubu}

Araştırmanın evreni Beşiktaş Jimnastik Kulübü Basketbol Altyapı takımlarında (U18, U16, U15,U24, U13, U12, U11) spor faaliyetini sürdüren sporcular oluşturmaktadır. Araştırmanın örneklemini ise tesadüfi yöntemle seçilmiş, spor faaliyetini aktif olarak sürdüren 101'i kadın $(\% 55,2)$ ve 82 'si erkek $(\% 44,8)$ olmak üzere toplam 183 gönüllü sporcu 
oluşturmaktadır. Çalışmaya katılan sporculara ölçme araçları açıklama yapılarak yüzyüze uygulanmıştır.

\section{Veri Toplama Araçları}

Bu çalışmada veri toplama aracı olarak anket yöntemi kullanılmıştır. Anketin ilk bölümünde katılımcılara yönelik demografik sorular yer alırken kinci bölümde ise "Algılanan Liderlik" ölçeği kullanılmıştır. Bu ölçek, Ekvall ve Arvonen (1991: 17-26) tarafından geliştirilmiştir ve Tengilimoğlu (2005) tarafından 596 kişi üzerinde uygulanan ölçeğin güvenilirliği için yapılan analiz sonucunda, Cronbach Alpha değeri 0,963 olarak bulunmuştur (Tengilimoğlu, 2005: 8). Ölçek toplam 36 maddeden oluşmaktadır. Liderlik davranışlarına ilişkin verilen ifadeler 3 tip liderlik davranış özelliklerini belirlemeye yönelik hazırlanmış olup sorular karışık verilmiştir. 14 madde $(1,2,4,7,10,13,16,19,22,25,28,31$, 32, 34) işgören odaklı (Employee-orientation) liderlik davranış özelliklerini, 12 madde (3, $6,9,12,15,18,21,24,27,30,33,36)$ üretim odaklı (Productionorientation) liderlik davranış özellikleri ve 10 madde ise $(5,8,11,14,17,20,23,26,29$, 35) değişim odaklı (transformasyonel veya Change-orientation) liderlik davranışını ifade etmektedir. Ölçekteki maddeler için 5’li Likert ölçeği kullanılmıştır.

\section{Verilerin Analizleri}

Elde edilen veriler SPSS 24.0 paket programında tanımlayıcı istatistikler, Normal dağılım gösteren değişkenler için bağımsız iki toplum ortalamasına dayalı iki örneklem $\mathrm{T}$ testi, normal dağılıma uymayanlar değişkenler için Mann Whitney U ve takımlar arasında farklılığı tespit etmek için ANOVA analizleri yapılmıştır. Anlam düzeyi 0.05 olarak alınmıştır. Ayrıca toplanan verilerle ölçeğin geçerlik analizi yapıldığında Cronbach alfa değeri 0,963 olarak bulunmuştur. Bu değer ölçeğin geçerliğinin oldukça yüksek olduğunu ifade etmektedir. 


\section{Bulgular}

Elde edilen bulgular aşağıdaki tablolarda sunulmaktadır.

Tablo 1. Katılımcıların Cinsiyet ve Yaş Değişkenine Göre Dağılımı

\begin{tabular}{|c|c|c|c|c|}
\hline Cinsiyet & Takım & Yaş & $\mathbf{N}$ & $\%$ \\
\hline \multirow{11}{*}{ Kadın } & U18 & $15-18$ & 18 & 100 \\
\hline & & 15 altı & 3 & 27,3 \\
\hline & U16 & $15-18$ & 8 & 72,7 \\
\hline & & Toplam & 11 & 100 \\
\hline & & 15 altı & 6 & 42,9 \\
\hline & U15 & $15-18$ & 8 & 57,1 \\
\hline & & Toplam & 14 & 100 \\
\hline & U14 & 15 altı & 12 & 100 \\
\hline & U13 & 15 alt1 & 11 & 100 \\
\hline & U12 & 15 altı & 14 & 100 \\
\hline & U11 & 15 altı & 21 & 100 \\
\hline \multirow{7}{*}{ Erkek } & U18 & & & \\
\hline & U16 & $15-18$ & 11 & 100 \\
\hline & U15 & $15-18$ & 10 & 100 \\
\hline & U14 & 15 altı & 14 & 100 \\
\hline & U13 & 15 altı & 12 & 100 \\
\hline & U12 & 15 alt1 & 18 & 100 \\
\hline & U11 & 15 altı & 17 & 100 \\
\hline
\end{tabular}

Kadınlarda U18 takımı 15 - 18 yaş aralığındadır (Tablo 1). U16 takımında \%27,3'ü 15 yaş altı ve $\% 72,7^{\prime}$ 'si 15 - 18 yaş arası kadın sporculardan oluşmaktadır. U15 takımında $\% 42,9^{\prime}$ u 15 yaş altı ve $\% 57,1^{\prime}$ i 15 - 18 yaş arası kadın sporculardan oluşmaktadır. U14, U13, U12 ve U11 kadın takımlarında sporcuların tamamı 15 yaş altıdır.

Erkeklerde, U16 ve U 15 takımında sporcuların tamamı 15 - 18 yaş aralığında iken (Tablo 1), U14, U13, U12 ve U11 takımlarında ise sporcuların tamamı 15 yaş altıdır.

Kadın sporcuların millilik dağılımlarına bakıldığında (Tablo 2), yalnızca U18 takımında 8 kadın sporcu $(\% 44,4)$, U16 takımında 1 kadın sporcu $(9,1)$ ve U14 takımında 1 kadın sporcu $(\% 8,3)$ milli sporcu olmuştur. Diğer takımlarda (U15, U13, U12 ve U11) milli kadın sporcu bulunmamaktadir. 
Tablo 2. Katılımcıların Millilik Değişkenine Göre Dağılımı

\begin{tabular}{|c|c|c|c|c|}
\hline Cinsiyet & Takımınız & Millilik & $\mathbf{N}$ & $\%$ \\
\hline \multirow{13}{*}{ Kadın } & \multirow{3}{*}{ U18 } & Evet & 8 & 44,4 \\
\hline & & Hayır & 10 & 55,6 \\
\hline & & Toplam & 18 & 100 \\
\hline & \multirow{3}{*}{ U16 } & Evet & 1 & 9,1 \\
\hline & & Hayır & 10 & 90,9 \\
\hline & & Toplam & 11 & 100 \\
\hline & U15 & Hayır & 14 & 100 \\
\hline & \multirow{3}{*}{$\mathrm{U} 14$} & Evet & 1 & 8,3 \\
\hline & & Hayır & 11 & 91,7 \\
\hline & & Toplam & 12 & 100 \\
\hline & U13 & Hayır & 11 & 100 \\
\hline & U12 & Hayır & 14 & 100 \\
\hline & U11 & Hayır & 21 & 100 \\
\hline \multirow{6}{*}{ Erkek } & U16 & Hayır & 11 & 100 \\
\hline & U15 & Hayır & 10 & 100 \\
\hline & U14 & Hayır & 14 & 100 \\
\hline & U13 & Hayır & 12 & 100 \\
\hline & U12 & Hayır & 18 & 100 \\
\hline & U11 & Hayır & 17 & 100 \\
\hline
\end{tabular}

Erkek sporcuların millilik dağılımlarına bakıldığında ise (Tablo 2), hiçbir takımdan erkek milli sporcu henüz çıkmamıştır.

Kadın sporcuların kaç yıldır bu takımlarda bulundukları incelendiğinde (Tablo 3), U18 takımı için \%16,7'si 1 yıldan az bir süredir, $\% 44,4^{\prime} \ddot{\text { u }} 2-3$ yıldır ve \%38,9'u ise $4-5$ yıldır takımdadır. U16 kadın takımı için, \%27,3'ü 1 yıldan az bir süredir, \%45,5'i 2 - 3 yıldır, \%18,2'si ise $4-5$ yıldır ve \%9,1'i 5 yıldan fazla bir süredir takımdadır. U15 kadın takımı için $\% 7,1^{\prime}$ i 1 yıldan az bir süredir, \%64,3'ü 2 - 3 yıldır ve $\% 28,6$ 'sı ise $4-5$ yıldır takımdadır. U14 kadın takımı için, \%50,0'si 1 yıldan az bir süredir, $\% 41,7^{\prime}$ si 2 - 3 yıldır ve $\% 8,3$ 'ü 5 yıldan fazla bir süredir takımdadır. U13 kadın takımı için, \%36,4'ü 1 yıldan az bir süredir ve \%63,6'sı 2 - 3 yıldır takımdadır. U12 kadın takımı için \%42,9'u 1 yıldan az bir süredir, \%35,7'si $2-3$ yıldır ve \%21,4'ü ise $4-5$ yıldır takımdadır. U11 kadın takımı için, $\% 81,0^{\prime} 11$ yıldan az bir süredir ve \%19,0'1 2 - 3 yıldır takımdadır. 
Beşiktaş Jimnastik Kulübü Basketbol Altyapı Takımları Antrenörlerinin Liderlik Özelliklerinin Belirlenmesi

Tablo 3. Katılımcılarınn Kaç Yıldır Bu Takımın Bir Mensubusunuz Değişkenine Göre Dă̆ılımı

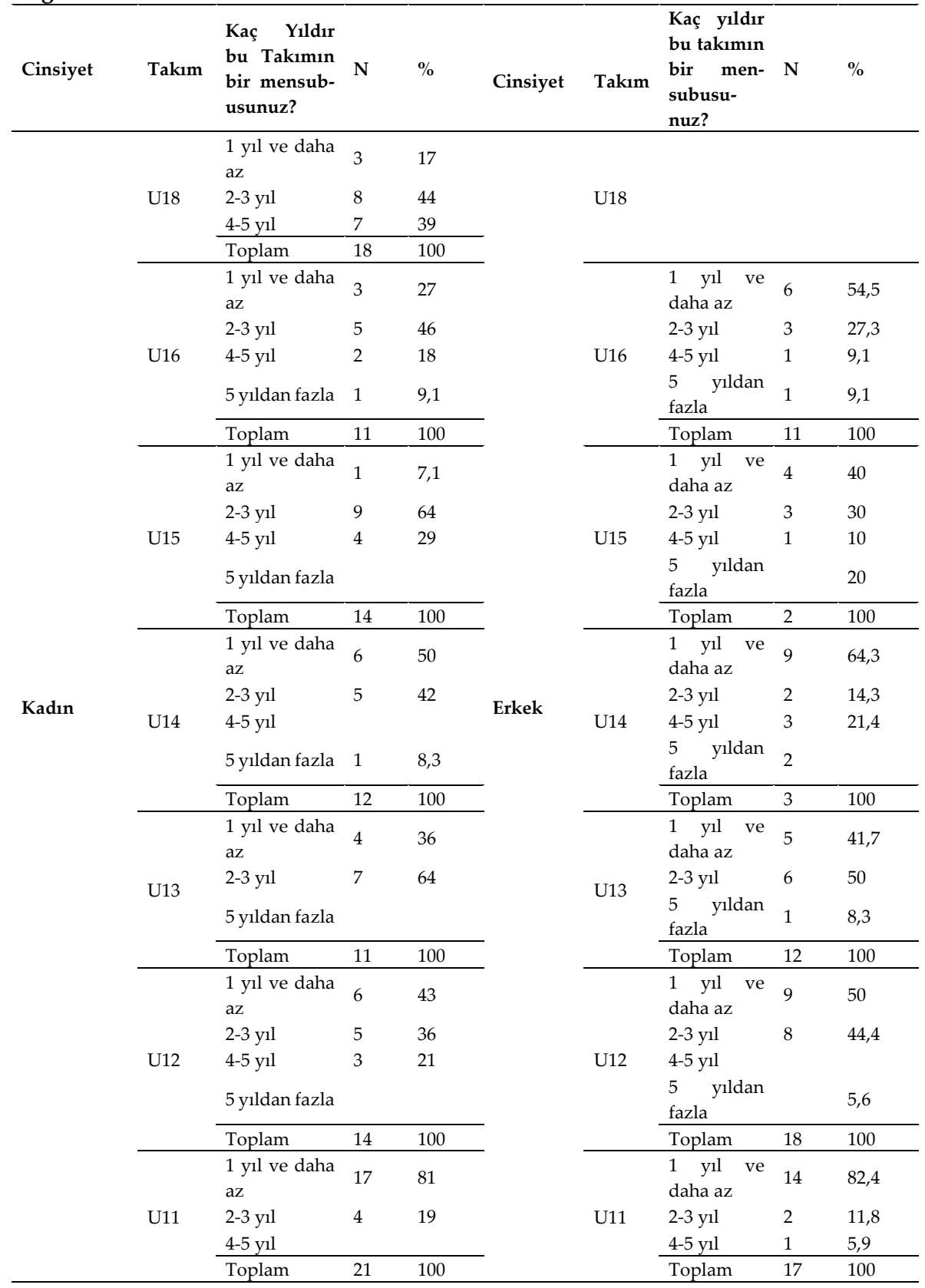


Erkek sporcuların kaç yıldır bu takımlarda bulundukları incelendiğinde (Tablo 3), U16 takımı için, \%54,5'i 1 yıldan az bir süredir, $\% 27,3$ 'ü 2 - 3 yıldır, $\% 9,1^{\prime}$ i ise $4-5$ yıldır ve $\% 9,1$ 'i 5 yıldan fazla bir süredir takımdadır. U15 erkek takımı için, \%40,0'ı 1 yıldan az bir süredir, \%30,0'1 2 - 3 yıldır, \%10,0'1 ise $4-5$ yıldır ve \%20,0'1 5 yıldan fazla bir süredir takımdadır. U14 erkek takımı için \%64,3'ü 1 yıldan az bir süredir, \%14,3'ü $2-3$ yıldır ve \%21,4'ü ise $4-5$ yıldır takımdadır. U13 erkek takımı için, $\% 41,7$ 'si 1 yıldan az bir süredir, \%50'si 2 - 3 yıldır ve \%8,3'ü 5 yıldan fazla bir süredir takımdadır. U12 erkek takımı için, \%50'si 1 yıldan az bir süredir, \%44,4'ü 2 - 3 yıldır ve \%5,6'sı 5 yıldan fazla bir süredir takımdadır. U11 erkek takımı için \%82,4'ü 1 yıldan az bir süredir, \%11,8'i 2 - 3 yıldır ve $\% 5,9^{\prime} u$ ise $4-5$ yıldır takımdadır.

Tablo 4. Katılımcıların Algılarına Göre Tanımlayıcı İstatistiklerine İlişkin Dağılımı

\begin{tabular}{|c|c|c|c|c|c|}
\hline \multicolumn{2}{|c|}{ Cinsiyet } & \multirow{2}{*}{$-\frac{\mathbf{N}}{101}$} & \multirow{2}{*}{$\begin{array}{l}\text { En Küçük } \\
41,00\end{array}$} & \multirow{2}{*}{$\begin{array}{l}\text { En Büyük } \\
180,00\end{array}$} & \multirow{2}{*}{$\frac{\bar{x} \pm \mathrm{SS}}{157,94 \pm 23,73}$} \\
\hline toplam & & & & & \\
\hline Kadın & işgoren & 101 & 19,00 & 70,00 & $62,04 \pm 9,20$ \\
\hline üretim & & 101 & 12,00 & 60,00 & $53,84 \pm 7,99$ \\
\hline değişim & & 101 & 13,00 & 50,00 & $42,90 \pm 6,64$ \\
\hline toplam & & 82 & 53,00 & 179,00 & $151,57 \pm 20,05$ \\
\hline Erkek & işgoren & 82 & 25,00 & 70,00 & $59,87 \pm 7,64$ \\
\hline üretim & & 82 & 17,00 & 60,00 & $51,84 \pm 6,63$ \\
\hline değiş̧im & & 82 & 14,00 & 50,00 & $41,09 \pm 6,28$ \\
\hline
\end{tabular}

Tablo 4'e göre, kadın sporcuların hem algılayıcı liderlik genelinde hem de işgören, üretim ve değişim alt boyutlarında puan ortalamaları erkek sporculardan daha yüksektir.

Tablo 5. Katılımcıların Cinsiyet Değişkenine Göre Liderlik Ölçeği Toplam Puan ve Alt Boyutlarına Ait Tanımlayıcı İstatistik ve P Değerleri

\begin{tabular}{|c|c|c|c|c|c|c|c|c|}
\hline & Cinsiyet & $\mathbf{N}$ & En Küçük & En Büyük & $\bar{x}$ & SS & $\mathrm{Z}$ & p \\
\hline \multirow{2}{*}{ Toplam } & Kadın & 101 & 41 & 180 & 157,94 & 23,73 & \multirow{2}{*}{$-3,130$} & \multirow{2}{*}{, $002^{*}$} \\
\hline & Erkek & 82 & 53 & 179 & 151,57 & 20,05 & & \\
\hline \multirow{2}{*}{ İşgören } & Kadın & 101 & 19 & 70 & 62,04 & 9,20 & \multirow{2}{*}{$-2,884$} & \multirow{2}{*}{, $004^{*}$} \\
\hline & Erkek & 82 & 25 & 70 & 59,87 & 7,64 & & \\
\hline \multirow{2}{*}{ Üretim } & Kadın & 101 & 12 & 60 & 53,84 & 7,99 & \multirow{2}{*}{$-3,412$} & \multirow{2}{*}{, $001^{*}$} \\
\hline & Erkek & 82 & 17 & 60 & 51,84 & 6,63 & & \\
\hline \multirow{2}{*}{ Değişim } & Kadın & 101 & 13 & 50 & 42,90 & 6,64 & \multirow{2}{*}{$-2,471$} & \multirow{2}{*}{, $013^{*}$} \\
\hline & Erkek & 82 & 14 & 50 & 41,09 & 6,28 & & \\
\hline
\end{tabular}

${ }^{*} p<0.05$ 
Katılımcıların cinsiyet değişkenine göre algılanan liderlik ölçeği toplam puanlarının ve alt boyutlarının Mann-Whitney U Testi sonuçlarına (Tablo 5) göre toplam puanlarının ve işgören, üretim ve değişim davranış özellikleri ortalamalarında istatistiksel olarak anlamlı bir farklılık bulunmuştur $(\mathrm{p}<0.05)$.

Tablo 6. Liderlik Ölçeğine Ait Toplam Puan ve Alt Kategorilerine Ait Gruplar Arası P Değerleri

\begin{tabular}{|c|c|c|c|c|c|c|c|}
\hline & & Kareler Toplamı & df & $\begin{array}{l}\text { Kareler } \\
\text { mas1 }\end{array}$ & Ortala- & $\mathbf{F}$ & Sig. \\
\hline \multirow{2}{*}{ Toplam } & Gruplar Arası & 9146,893 & 6 & 1524,482 & & \multirow{2}{*}{3,288} & \multirow{2}{*}{, $004^{*}$} \\
\hline & Grup İçi & 81597,708 & 176 & 463,623 & & & \\
\hline \multirow{2}{*}{ İssgoren } & Gruplar Arası & 1545,629 & 6 & 257,605 & & \multirow{2}{*}{3,819} & \multirow{2}{*}{, $001^{*}$} \\
\hline & Grup İçi & 11871,300 & 176 & 67,451 & & & \\
\hline \multirow{2}{*}{ Üretim } & Gruplar Arası & 1044,575 & 6 & 174,096 & & \multirow{2}{*}{3,369} & \multirow{2}{*}{, $004^{*}$} \\
\hline & Grup İçi & 9094,878 & 176 & 51,675 & & & \\
\hline \multirow{2}{*}{ Değişim } & Gruplar Arası & 602,480 & 6 & 100,413 & & \multirow{2}{*}{2,469} & \multirow{2}{*}{, $026^{*}$} \\
\hline & Grup İçi & 7158,941 & 176 & 40,676 & & & \\
\hline
\end{tabular}
${ }^{*} \mathrm{p}<0.05$

Katılımcıların liderlik ölçeği toplam puanlarının ve alt boyutlarının ANOVA sonuçlarına (Tablo 6) göre toplam puanlarının ve işgören, üretim ve değişim davranış özellikleri ortalamalarında istatistiksel olarak anlamlı bir farklılık bulunmuştur $(\mathrm{p}<0.05)$.

Tablo 7. Katılımcıların Liderlik Ölçeği Toplam Puanlarının ve Alt Kategorilerinin Farkın kaynaklandı̆̆ı Gruba Ait P Değerleri

\begin{tabular}{|c|c|c|c|c|c|c|}
\hline & Grup & $\mathbf{N}$ & $\bar{x}$ & $\begin{array}{l}\text { Standart } \\
\text { Sapma }\end{array}$ & FARK & p \\
\hline \multirow{3}{*}{ TOPLAM } & U16 & 22 & 167,40 & 12,39 & U16-U15 & $.013^{*}$ \\
\hline & U15 & 24 & 145,12 & 25,85 & & $.013^{*}$ \\
\hline & U14 & 26 & 146,57 & 28,58 & U16-U14 & $.039^{*}$ \\
\hline \multirow{4}{*}{ İŞGÖREN } & U18 & 18 & 59,50 & 6,82 & U16-U18 & $.025^{*}$ \\
\hline & U16 & 22 & 66,18 & 4,26 & U16-U15 & $.006^{*}$ \\
\hline & U15 & 24 & 56,70 & 10,47 & U16-U14 & $.018^{*}$ \\
\hline & U14 & 26 & 58,26 & 10,08 & & $.018^{*}$ \\
\hline \multirow{2}{*}{ ÜRETİM } & U16 & 22 & 55,95 & 4,18 & U16-U14 & $.045^{*}$ \\
\hline & U14 & 26 & 49,46 & 10,12 & & $.045^{*}$ \\
\hline \multirow{2}{*}{ DEĞİŞìM } & U16 & 22 & 45,50 & 4,30 & U16-U15 & $.038^{*}$ \\
\hline & U15 & 24 & 39,70 & 7,23 & & $.038^{*}$ \\
\hline
\end{tabular}

${ }^{*} \mathrm{p}<0.05$ 
Katılımcıların liderlik ölçeği toplam puanlarının ve alt boyutlarının Tamhane test sonuçlarına (Tablo 7) göre algılana liderlik ölçeğinden davranış özellikleri puanlardaki farklılık; toplam puanlarda 16 ile 14 ve 15, işgören 16 ile 18, 15 ve 14 ve değişim 16 ile 15 den kaynaklanmaktadır.

\section{Tartışma ve Sonuç}

Beşiktaş Jimnastik Kulübü Basketbol altyapı takım sporcularının antrenörleri hakkındaki liderlik özelliklerinin belirlenmesi amacıyla yapılan çalışmada, cinsiyet değişkenine göre bakıldığında, sporcuların genel olarak liderlik algıları, kadınların lehine anlamlı farklılaşma göstermektedir. Ayrıca, sporcuların liderlikte üretim algıları yine kadınlarda daha yüksek bulunurken, işgören ve değişim algılarının hem erkek hem de kadın sporcularda hemen hemen eşit olduğu ortaya çıkmıştır. Literatürde cinsiyete göre liderlik algıları incelendiğinde farklı sonuçlar görülmektedir. Ödemiş ve Karagün (2016), dans sporcuları üzerinde yaptıkları araştırmada cinsiyete göre liderlik algılarının anlamlı olarak farklılaşmadığı sonucuna varılmıştır. Bu sonuç yapılan çalışmayla çelişki göstermektedir. Weinberg ve Gould (2003), yaptıkları çalışmada erkek sporcuların, eğitim ve öğretici davranışları ve otokratik bir koçluk stilini kadınlardan daha fazla tercih ettiğini ve kadın sporcuların da daha demokratik koçluk davranışlarını tercih ettiklerini bildirmiştir. Rodrigez (2004) yüzücülerde yaptığı çalışmada, cinsiyet ve liderlik arasında erkek sporcuların, otokratik lider davranışı algılarının daha yüksek düzeyde olduğunu ve anlamlı farklılaştığını rapor etmiştir. Naidoo, Coopoo, Surujlal (2015) yüzücüler üzerinde yapılan liderlik algılamaları araştırmasında, hem erkek hem de kadın spor yöneticileri için dönüşümcü liderlik tarzının baskın olduğunu, erkek spor yöneticilerinin kadın spor yöneticilerinden daha yüksek bir ortalama puan aldığını, yani yüzücülerin cinsiyete göre liderlik algılarında anlamlı farklılaşma bulduklarını ortaya koymuşlardır. Bu bulgular çalışmadan elde edilen sonuçlarla tutarlılık göstermektedir. Horn (2002), özel koçluk davranışları için erkek ve kadın tercihleri arasındaki farklardan daha fazla benzerlikler bulmuştur. Kadın sporcular, erkek sporculardan daha fazla sosyal destek ve otokratik davranışları tercih ederken erkek sporcular, kadın sporculardan daha fazla eğitim ve öğretim davranışı tercih ettiğini belirtmektedir. Eskiyecek, Bayazıt, Sarı (2015) 
sporcuların cinsiyet değişkenine göre otokratik davranışta istatistiksel olarak anlamlı bir farklılık bulunduğunu fakat eğitici ve öğretici, demokratik, sosyal destek ve pozitif geribildirim antrenör davranışlarında istatistiksel olarak anlamlı bir farklılık bulunmadığını ifade etmişlerdir.

Yapılan çalışmada, takımlara göre algılanan liderlik ölçeğinin tamamı ile işgören, üretim ve değişim alt boyutlarına ait davranış özellikleri ortalamarında istatistiksel olarak anlamlı bir farklılık bulunmuştur $(\mathrm{p}<0.05)$. Bu farklılık, ölçeğin tamamında U16 ile U14 ve U15 takımları arasında, işgören davranışı için U16 ile U18, U15 ve U14 takımları arasında, üretim davranışı için U16 ve U14 takımları arasında ve değişim davranışı için U16 ile U15 takımları arasında olmaktadır. Bunun nedeni, çalışmada belirlenen takımların gruplandırılması sporcuların yaş gruplarına göre yapıldığından dolayı, takımlara göre liderlik algısının anlamlı farklılaşmasını, aslında sporcuların yaşlarına göre liderlik algılarının farklılaşmasına bağlamak mümkün olabilir. Literatür araştırmasının sonucuna göre, Chelladurai ve Carron (2013), otokratik koçluk davranış tercihinin yaş bazında atletik olgunluğa bağlı olarak arttı̆̆ını bulmuşlardır. Terry (2004), koç liderlik ölçeğinin beş boyutunda yaş farkı bulmamıştır. Sporcuların yaş seviyesi daha düşük olduğunda, antrenörler daha fazla eğitim ve öğretim, otokratik, sosyal destek, olumlu geri bildirim ve durumsal değerlendirme davranışı uygular. Sporcunun yaş seviyesi arttıkça koçların daha az demokratik davranışlar sergilediği görülmektedir (Perrera ve Pushpakumari, 2015). Eskiyecek, Bayazıt, Sarı (2015) sporcuların yaş değişkenine göre eğitici ve öğretici, demokratik, sosyal destek ve pozitif geribildirim davranışlarında istatistiksel olarak anlamlı bir farklılık gösterdiğini rapor etmiştir. Ödemiş ve Karagün (2016) dans sporcularının yaş durumlarına göre tercih ettikleri liderlik davranışı karşılaştırıldığında anlamlı bir fark bulunduğunu ve alt boyutlara yanısyan şekliyle otokratik davranış, sosyal destek ve pozitif geri bildirimde istatiksel olarak anlamlı bir fark olduğunu bildirmişlerdir. Konter (2009) sporcuların yaş gruplarına göre liderlik zorlayıcı gücü, uzmanlık gücü ve yasal gücü algılarında anlamlı bir farklılık bulunmazken, özdeşleşim gücü algısında anlamlı bir farklılık bulunduğunu ortaya çıkarmışlardır. Bu araştırmaların bulguları, yapılan çalışmada elde edilen bulgular ile benzerlik göstermektedir. 
Kadın sporcuların antrenörlerine yönelik liderlik algıları erkek sporcularınkinden istatistiksel olarak anlamlı bir farklılık göstermektedir $(\mathrm{p}<0.05)$. Bunun nedenini de kadınların erkeklerden faklı bir duygusal ve ruhsal yapısı olmasının yanısıra yetiştirilme biçimlerindeki farklılıkların etkili olabileceği nedenine bağlamak mümkün olabilir. Ayrıca sporcuların yaşlarına göre de liderlik algılarında anlamlı farklılaşma tespit edilmiştir $\mathrm{p}<0.05)$. Bunun nedeni ise, genel olarak insanların yaşlarına göre bir konuyu algılama ve kavrayış düzeylerinin farklı olması olarak gösterilebilir.

Toros ve Duvan (2011) tarafından yapılan bir çalışmada, farklı olan antrenörlük algıları tepkilerini ölçmede değerlendirmelerin yapılmasına olanak sağlayan ileriye dönük desenlerin kullanılmasını ( 3 yıl- 5 yıl gibi) ve daha nesnel sonuçlar elde edilmesini sağlayabileceğini belirtmişlerdir. Türksoy ve Şarkıcı (2003-2011) tarafından yapılan çalışmada, antrenör özellikleri kriter alındığında, futbolcunun antrenöründe algıladığı gerçek liderlik davranışı ile tercih ettiği lider davranışı ve aldığı tatminde anlamlı farklılığa rastlanmazken sporcunun özellikleri dikkate alınarak yapılan analizlerde anlamlı farklılıklara rastlandığı görülmüştür.

Sonuç olarak, araştırmaya katılan kadın sporcuların antrenörleri hakkında algıladıkları işgören, üretim ve değişim liderlik davranış özelliklerini erkek sporculara göre daha fazla benimsedikleri sonucuna varılmıştır. Bu sonuca göre, kadın sporcuların antrenörleri hakkındaki liderlik algıları açısından erkeklere nazaran daha hassas oldukları düşünülebilinir.

Antrenörlerin özellikle erkek sporculara yönelik işgören, üretim ve değişim liderlik davranış özelliklerini daha fazla göstermeleri beklenmektedir. 


\title{
EXTENDED ABSTRACT
}

\section{Designating The Leadership Specialities of The Coaches of Besiktas Gymnastic Club's Youth Teams}

\author{
Ayşe Demir - Betül Bayazıt - Serap Çolak \\ Kocaeli University
}

The concept of leadership can be dated to the early days of humanity. The concept has been used academically since the first half of the 19th century. "Group" is one of the basic concepts of sociology. For groups to work, come together and organize, group leadership requires certain features such as authority, role, communication and sociometric structure. In general, it is stated in the literature that people will always need leaders because they are a social entity, that leadership will not lose importance, that leaders will need more intensity in organizations in the future and that leaders who understand the complexity of the rapidly changing global environment will need to be effective in today's organizations. For such reasons, leadership has been a concept that has been continuously developed by researchers since its emergence or recognition. Leadership is basically defined as the ability to persuade people to volunteer for a specific purpose. Many of the definitions of leadership in Turkish literature are to lead a group, to motivate employees to make their work more efficient, to gather a group of people for a specific purpose, to identify problems and to offer solutions to members. To put it simply, leadership is the ability to influence, motivate, and guide other members of the organization to achieve their goals. Coaches have the potential to influence group cohesion. These leadership factors can have direct or indirect impact through individual intervention or team factors. The special emphasis given to team unity by coaches is the basic principle behind the success of the team and therefore they use some techniques to ensure that the spirit of intimacy and unity exists among the team members. It can be seen that the role of a coach as a leader has become evident in the harmony of team members. Although there are many approaches to leadership style and behavior in the literature, it is seen that there is relatively little research in this field due to the lack of suggested theories and specialized models in 
sports. Therefore, the aim of this study was to determine the leadership characteristics of Beşiktaş Gymnastics Club Basketball infrastructure team athletes' coaches.

In this context, the aim of this study is to examine the perceptions of the athletes about the leadership behaviors of the coaches and to determine the basic leadership traits of the athletes engaged in team sports and their perceptions about the leadership traits.

In this research, 101 women (55.2\%) and 82 men (44.8\%) who are actively engaged in sports activities in Beşiktaş Gymnastics Club Basketball Infrastructure teams (U18, U16, U15, U24, U13, U12, U11) A total of 183 athletes participated voluntarily. In this research, data were collected using "Perceived Leadership Scale". The scale consists of 36 items. The statements about the leadership behaviors of the athletes about their coaches were prepared to determine the leadership behavior characteristics of 3 types (employee, production and change). 14 items $(1,2,4,7,10,13,16,19$, $22,25,28,31,32,34)$ show employee-orientation leadership behavior characteristics, 12 items $(3,6,9)(12,15,18,21,24,27,30,33,36)$ productionoriented (Productionorientation) leadership behavioral characteristics and 10 items $(5,8,11,14,17,20,23,26,29,35)$ refers to transformational or change-orientation leadership behavior. A 5-point Likert scale was used for the items in the scale. Data obtained were analyzed using SPSS 24.0 descriptive statistics, two samples $\mathrm{T}$ test based on independent two-population means for normal distribution, Mann Whitney $U$ for variables that do not fit normal distribution, and ANOVA analysis to determine differences between teams. Meaning level was taken as 0.05 . In addition, when the validity analysis of the scale was performed with the collected data, Cronbach's alpha value was found to be 0.963 . According to the obtained data, a statistically significant difference was found between the teams in terms of leadership scale total scores (employee, production, change) about the coaches of the team players $(\mathrm{p}<0.05)$. A statistically significant difference was also found in leadership total scores (employee, production, change) according to the gender variable of the teams $(p<0.05)$. In addition, there was a significant difference in leadership perceptions according to the age of the athletes ( $\mathrm{p}<0.05)$. 
As a result, it was concluded that the female athletes who participated in the research adopted more employee, production and change leadership behavior characteristics about their coaches than male athletes. When all the results were examined, it was concluded that women were more sensitive than men to leadership perceptions about their coaches.

\section{Kaynakça / References}

Almeida, P. L. ve Lameiras, J. (2013). You'll never walk alone: Cooperation as an explanatory paradigm of the dynamics of sports tea. Revista de Psicología del Deporte, 22(2), 34-48.

Başer, E. (1998). Uygulamalı spor psikolojisi. Ankara: Bağırgan Yayımevi..

Brandão, R. ve Carchan, D. (2010). Preferred leadership behavior and their influence on athletes' performance. Motricidade, 6(1), 53-69.

Büyüköztürk, Ş., Çakmak, E. K., Akgün, Ö. E., Karadeniz, Ş. ve Demirel, F. (2014). Bilimsel araştırma yöntemleri. (18. Baskı) Ankara: Pegem Akademi.

Carvalho, M., Martins, L., ve Portela, S. L. (2013). Leadership and commitment on Portuguese rugby national team. International Journal of Academic Research, 5(2), 187-191.

Chelladurai, P., ve Carron, AV., (2013). Athlete maturity and preferred leadership. J Sport Psychol, 5, 371-380 .

Deniz, M.E., (2002). Üniversite öğrencilerinin karar verme stratejileri ve sosyal beceri düzeylerinin TA-baskın ben durumları ve bazı özlük niteliklerine göre karşılaştırmalı olarak incelenmesi (Doktora Tezi). Selçuk Üniversitesi, Sosyal Bilimler Enstitüsü, Konya.

Doğan, O. (2005). Spor psikolojisi. Ankara: Nobel Kitabevi.

Ekvall, G. ve Arvonen J. (1991). Change-centred leadership:An extension of the two dimensional model. Scandinavian Journal of Management, 7, 726.

Eskiyecek, C. G., Bayazıt, B., ve Sarı, İ. (2015). Sporcularda tercih edilen antrenör liderlik davranışlarının yaş, cinsiyet ve spor dalı açısından incelenmesi (Diyarbakır Örneği). Uluslararası Hakemli Akademik Spor Sağllk ve Tip Bilimleri Dergisi, 5, 27- 42.

Fenoy, J. ve Campoy, L. (2012). Sports performance, leadership styles and experiential avoidance in young Almerian footballers. Revista de Psicología del Deporte, 21(1), 137-142. 
García-Mas, A., Olmedilla, A., Ortega, E., Almeida, P. L., Lameiras, J., Sousa, C., ve Cruz, J. (2009). Cooperation and cohesion in football teams in competition. International Journal of Hispanic Psychology, 2(1), 29-46.

Heppner, P. P., ve Krauskopf, C. J. (1987). The integration of personal problem solving processes within counseling. The Counseling Psychologist, 15, 371-447.

Horn T (2002). Advances in sport psychology. Champaign, IL: Human Kinetics.

Kleinert, J., Ohlert, J., Carron, B., Eys, M., Feltz, D., Harwood, C., ... Sulprizio, M. (2012). Group dynamics in sports: an overview and recommendations on diagnostic and intervention. The Sport Psychologist, 26(3), 412434

Konter, E. (2009). Antrenörlerin ve sporcuların liderlik gücü algıları. Türk Psikolojik Danışma ve Rehberlik Dergisi, 4(31), 61-68

Lameiras, J., Almeida, P. L., ve García-Mas, A. (2014). Relationship between cooperation and goal orientation among professional and semiprofessional team players. Perceptual \& Motor Skills, 119(3), 851-860.

Moen, F. (2014). The coach-athlete relationship and expectations. International Journal of Humanities and Social Science, 4(11), 29-40.

Naidoo, P., Coopoo, Y., ve Surujlal, J. (2015). Perceived leadership styles of sport administrators and the relationship with organisational effectiveness. African Journal for Physical, Health Education, Recreation and Dance, November (Supplement 1), 167-181.

Northouse, P.G. (2013). Leadership: Theory and practice. CA:Sage.

Olmedilla, A., Ortega, E., Almeida, P. L., Lameiras, J., Villalonga, T., Sousa, C., ... García-Mas, A. (2011). Cohesion and cooperation in sports teams. Anales de Psicología, 27(1), 232-238.

Ödemiş, M., Karagün, E., (2016). Dans sporcularının algıladıkları ve tercih ettikleri liderlik davranışları. Journal of Human Sciences, 13(3), 5201-5213. doi:10.14687/jhs.v13i3.4030

Perrera, H. ve Pushpakumari, D., (2015). The perception of athletes on the factors affecting to coach leadership behavior styles: An empirical study on leadership styles exhibited by the coaches of state universities in w...International Journal of Multidisciplinary Studies (IJMS), 2(2), page num 
Ponseti, F. J., Palou, P., Borràs, P. A., Vidal, J., Cantallops, J., Ortega, F., ... García-Mas, A. (2012). Disposition to cheating in sport questionnaire (CDED): Its application to young athletes. Revista de Psicología del Deporte, $21,75-80$.

Rodrigez, F. M. (2004). Perceived leadership in swimming: leadership styles of NCAA swim coaches and its relationships with athlete satisfaction, turnover intention, and commitment (Master of Science). B.A., Kenyon College, Georgia, Athens.

Sarı, İ., Ilić, J., ve Ljubojević, M. (2013). The comparison of task and ego orientation and general self-esteem of Turkish and Montenegrin young basketball players. Kinesiology, 45(2), 203-212.

Sauer, P. (2017). Effective leadership in sports. http://thesportdigest.com/2017/04/effective-leadership-in-sports/ adresinden 16 Nisan 2018 tarihinde alınmıştır.

Spink, K. S., Wilson, K. S., Brawley, L. R., ve Odnokon, P. (2013). The perception of team environment: the relationship between the psychological climate and members' perceived effort in highperformance groups. Group Dynamics: Theory, Research, and Practice, 17(3), 150-161.

Tengilimoğlu, D. (2005). Hizmet işlerinde liderlik davranışları ile iş doyumu arasındaki ilişkinin belirlenmesine yönelik bir araştırma, ticaret ve turizm. Gazi Üniversitesi Ĕ̆itim Fakültesi Dergisi, 1, 23-45.

Terry, P.C., (2004). The coaching preferences of Elite athletes competing at Universidad '04.Can, J Appl Sport Sci., 9,201-8.

Toros, T., ve Duvan, A. (2011). Eskrimcilerde algılanan antrenörlük davranışı, kolektif yeterlik ve hedef yönelimleri arasındaki ilişki. Niğde Üniversitesi Beden Ĕ̆itimi ve Spor Bilimleri Dergisi, 5(1), 33-41

Toros, T., Salman, M., ve Sari, I. (2013). The comparison of sports coaches' preseason, in-season and post season leadership behaviours in terms of sport psychology. International Journal of Human Sciences, 10(1), 237245.

Türksoy, A., ve Şarkıcı, T. (2003-2011). 12-14 yaş futbolcuların antrenörlerinden algıladıkları ve tercih ettikleri lider davranışları ile ilgili sporcu tatmini. İstanbul Üniversitesi Spor Bilimleri Dergisi, 11(3), 200-203. 
Vella, S. A., Oades, L. G., ve Crowe, T. P. (2013). The relationship between coach leadership, the coach athlete relationship, team success, and the positive developmental experiences of adolescent soccer players. Physical Education and Sport Pedagogy, 18(5), 549-561.

Weinberg RS ve Gould D (2003). Foundations of sport and exercise psychology (3rded.). Champaign, IL: Human Kinetics.

\section{Kaynakça Bilgisi / Citation Information}

Demir, A., Bayazıt, B. ve Çolak, S. (2019). Beşiktaş jimnastik kulübü basketbol altyapı takımları antrenörlerinin liderlik özelliklerinin belirlenmesi. OPUS-Uluslararası Toplum Araştırmaları Dergisi, 13(19), 1600-1619. DOI: 10.26466/opus.577979 